\title{
Percepções de egressos sobre o desenvolvimento da competência clínica na formação
}

\section{do enfermeiro}

\author{
Perceptions of graduates on the development of clinical competence in nursing training \\ Percepciones de los egresados sobre el desarrollo de la competencia clínica en la formación en \\ enfermería
}

Recebido: 25/06/2021 | Revisado: 09/07/2021 | Aceito: 13/07/2021 | Publicado: 23/07/2021

Adriana Freitas de Almeida Finger
ORCID: https://orcid.org/0000-0002-0569-0317
Universidade Federal de Mato Grosso, Brasil
E-mail: drifinger@ hotmail.com
Andréia Correia de Souza Cioffi
ORCID: https://orcid.org/0000-0003-2396-9343
Universidade Federal de Mato Grosso, Brasil
E-mail: andreiacs81@gmail.com
Juarez Coimbra Ormonde Junior
ORCID: https://orcid.org/0000-0001-8032-5419
Universidade Federal de Mato Grosso, Brasil
E-mail: coimbra.juarez@gmail.com
Luciana Portes de Souza Lima
ORCID: https://orcid.org/0000-0003-1305-0499
Universidade Federal de Mato Grosso, Brasil
E-mail: lu_souz@ hotmail.com
Gímerson Erick Ferreira
ORCID: https://orcid.org/0000-0002-4039-0205
Universidade Federal de Mato Grosso, Brasil
E-mail: gimeferreira@gmail.com
Mara Regina Rosa Ribeiro
ORCID: https://orcid.org/0000-0002-7132-3005
Universidade Federal de Mato Grosso, Brasil
E-mail: mrrribeiro10@gmail.com

\section{Resumo}

Estudo descritivo, exploratório, de abordagem qualitativa, que teve como objetivo compreender a percepção de egressos de enfermagem sobre o desenvolvimento da competência clínica durante a graduação, e como se percebem aptos a exercê-la como enfermeiros. Os resultados foram apresentados a partir de três temas principais: 1) Elementos constitutivos da competência clínica e seu desenvolvimento no âmbito da graduação; 2) Dicotomias no processo ensino-aprendizagem e implicações no desenvolvimento da competência clínica; e, 3) Interação Professor-Aluno no desenvolvimento da competência clínica. As discussões dos temas versaram sobre a necessidade de articulação entre teoria e prática por meio da inserção precoce dos alunos em cenários de prática, a importância dos estágios supervisionados e sua potência para a mobilização de conhecimentos e sobre os impactos das interações interpessoais e processos avaliativos para o desenvolvimento da competência clínica em graduandos de enfermagem. O estudo possibilitou compreender a premente necessidade das instituições de ensino pensar a formação dos alunos de forma integrada aos serviços, ao destacar a importância da aproximação do aluno ao campo prático. No processo de formação, os alunos veem no professor e preceptor uma referência a ser mimetizada, e para tanto, necessitam que a relação seja permeada por atitudes de respeito, encorajamento e empatia.

Palavras-chave: Enfermagem; Educação em enfermagem; Ensino; Competência clínica.

\begin{abstract}
Descriptive, exploratory study with a qualitative approach, which aimed to understand the perception of nursing graduates about the development of clinical competence during graduation, and how they perceive themselves able to exercise it as nurses. The results were presented based on three main themes: 1) Constituent elements of clinical competence and its development during the graduation; 2) Dichotomies in the teaching-learning process and implications for the development of clinical competence; and 3) Teacher-Student Interaction in the development of clinical competence. Discussions of the themes focused on the need for articulation between theory and practice through the early insertion of students in practical scenarios, the importance of supervised internships and their power for the mobilization of knowledge and the impacts of interpersonal interactions and evaluation processes for the development of clinical competence in nursing students. The study made it possible to understand the pressing need
\end{abstract}


for educational institutions to think about the training of students integrated with practical scenarios, by highlighting the importance of bringing the student closer to the nurse assistance. In the training process, students see the teacher and preceptor as a reference to be mimicked, and for that, they need the relationship to be permeated by respect, encouragement and empathy.

Keywords: Nursing; Nursing education; Teaching; Clinical competency.

\section{Resumen}

Estudio descriptivo, exploratorio con abordaje cualitativo, que tuvo como objetivo comprender la percepción de los egresados de enfermería sobre el desarrollo de la competencia clínica durante el egreso, y cómo se perciben a sí mismos capaces de ejercerla como enfermeros. Los resultados se presentaron en base a tres temas principales: 1) Elementos constitutivos de la competencia clínica y su desarrollo en el ámbito de la graduación; 2) Dicotomías en el proceso de enseñanza-aprendizaje e implicaciones para el desarrollo de la competencia clínica; y 3) Interacción profesor-alumno en el desarrollo de la competencia clínica. Las discusiones de los temas se centraron en la necesidad de articulación entre teoría y práctica a través de la inserción temprana de los estudiantes en escenarios prácticos, la importancia de las pasantías supervisadas y su poder para la movilización del conocimiento y los impactos de las interacciones interpersonales y los procesos de evaluación para el desarrollo de competencia clínica en estudiantes de enfermería. El estudio permitió comprender la imperiosa necesidad de que las instituciones educativas piensen en la formación de los estudiantes de manera integrada con los servicios, destacando la importancia de acercar al alumno al campo práctico. En el proceso de formación, los alumnos ven al maestro y al preceptor como un referente a imitar, y para ello necesitan que la relación esté impregnada de actitudes de respeto, estímulo y empatía.

Palabras clave: Enfermería; Educación en enfermeira; Ensenãnza; Competencia clínica.

\section{Introdução}

A noção de competência é polissêmica, multifacetada, e envolve aspectos cognitivos, procedimentais, sócio-culturais, ético-políticos, dentre outros; engloba saberes em uso, ou seja, entregas em situações reais de prática acadêmica ou profissional. Ainda que a literatura divirja sobre nuances epistemológicas do conceito, há consenso em relação a esses elementos, como também no que se refere ao seu núcleo central, composto por conhecimentos (saberes adquiridos e acumulados); habilidades (entendidas como o saber-fazer específico da profissão); e atitudes (relacionadas ao saber agir, avaliar e decidir) (Unsworth Melling \& Porteous , 2020; Vreugdenhil \& Spek, 2018).

Nessa perspectiva, entende-se que a competência clínica guarda igual polissemia, e no campo da enfermagem revestese de sentidos multirreferenciais e multidimensionais. Assim, para fins deste estudo, a competência clínica é compreendida como o saber e o saber-fazer, ou seja, a capacidade de mobilizar conhecimentos teóricos e práticos para atuar frente a situações semelhantes e/ou inéditas que se apresentam no cotidiano do trabalho da enfermagem, num processo contínuo de (re)construção e aplicação do conhecimento (Benner, 1984).

Considera-se que para o desenvolvimento da competência clínica é essencial a aquisição de experiências, a partir do contato com cenários reais de prática, os quais possibilitam o aprendizado e expertise por meio da vivência repetida de situações concretas (Benner, 1984). Na formação em enfermagem, esse desenvolvimento ocorre mediante processo gradativo e dinâmico, aprimorado ao longo de toda a trajetória do estudante, na experiência com as práticas em saúde e a pluralidade de situações complexas com que interage (Rocha et al., 2019).

Apesar de desejável, a competência clínica nem sempre é plenamente desenvolvida, fato que pode estar atrelado a déficits na interação entre o enfermeiro preceptor e o aluno em campo de prática clínica, o que ao contrário, promoveria a melhora do desempenho e aprendizagem do estudante (Lüdke, Almeida \& Silva, 2017). Além disso, pode estar relacionado ao pouco tempo que o aluno permanece em campo prático, de modo a experienciar e desenvolver as competências profissionais do enfermeiro, com vistas à assistência segura, e minimização da dicotomia entre teoria e prática (Esteves et al., 2018).

Todavia, em que pesem os benefícios da competência clínica em enfermagem, seja no âmbito da formação ou dos serviços de saúde, os modos mais propositivos pelos quais esta pode ser desenvolvida ainda são pouco compreendidos, e, por isso, faz-se pertinente o desenvolvimento de estudos que identifiquem os meios para este favorecimento, na experiência de formação em enfermagem. 
Em âmbito internacional, a aquisição de competências clínicas importantes para a atuação profissional do futuro enfermeiro, em geral, estão relacionadas à comunicação terapêutica, à habilidade de se expressar adequadamente com os pares e com os pacientes, à utilização de evidências científicas para direcionar a assistência, à gestão de atividades no campo prático e em grupo, e à autorrealização profissional (Martínez-Momblán et al., 2020; Unsworth Melling \& Porteous, 2020).

Para tanto, é importante que nos contextos de prática, a exemplo do estágio supervisionado, o desenvolvimento da competência clínica do estudante de enfermagem esteja atrelado a fatores que valorizem a experiência discente, a confiança em si, a aprendizagem a partir dos erros, de maneira a estimular a criatividade e oportunizar experiências promissoras aos alunos (Sadeghi, Oshvandi \& Moradi, 2019).

No Brasil, o estágio supervisionado é considerado momento profícuo para o desenvolvimento de competências laborais (Esteves et al., 2018), pois oportuniza experiências reais com a profissão, favorece a aquisição de competências requeridas ao futuro enfermeiro, e confere aptidão aos estudantes para realizarem atividades sozinhos ou com pouca supervisão (Rocha et al., 2019).

Assim, os estágios curriculares assumem relevância ímpar durante a formação do profissional enfermeiro, pois tratase do período em que é oportunizado ao aluno o contato e permanência em cenários de prática e vivência da profissão, o que, na perspectiva adotada, fortalece o desenvolvimento da competência clínica (Benner, 1984). Portanto, o conhecimento de experiências de egressos de enfermagem sobre este desenvolvimento ao longo da formação, bem como a percepção dos mesmos acerca da aptidão para o exercício da prática profissional como enfermeiros, mostra-se relevante e necessário, por constituir importante indicador da formação de enfermagem, que pode contribuir para a reorientação de projetos pedagógicos e para o planejamento das práticas docentes e de preceptoria.

Na certeza de que a competência clínica deve ser um interesse à formação educacional em enfermagem, rumo à melhoria das práticas do enfermeiro nos serviços de saúde, e que o conhecimento atribuível aos reais benefícios do desenvolvimento da competência clínica em enfermagem tem sido requisitada (Leal et al., 2018), emerge a necessidade de estudos neste cerne, em especial pesquisas que considerem a experiência de egressos sobre o desenvolvimento desta durante a formação.

Justificada a inclinação para a investigação na problemática enunciada, o presente estudo orientou-se pelas seguintes questões: Qual a percepção de egressos sobre o desenvolvimento da competência clínica na graduação em enfermagem? Como estes se percebem preparados para exercê-la como enfermeiros? Para responder a essas indagações, objetivou-se compreender a percepção de egressos de enfermagem sobre o desenvolvimento da competência clínica durante a graduação, e como se percebem aptos a exercê-la como enfermeiros.

\section{Metodologia}

Estudo descritivo, exploratório, de abordagem qualitativa, realizado em uma universidade pública federal da região centro-oeste do Brasil, que atendeu às recomendações do Consolidated criteria for reporting qualitative research (COREQ) em sua versão traduzida para o português do Brasil (Souza et al., 2021).

Participaram 11 egressos de enfermagem, que atenderam aos seguintes critérios: ser egresso do curso de graduação em enfermagem da universidade em tela e, estar inserido no mercado de trabalho, como enfermeiro, há pelo menos um ano. Para tanto, utilizou-se o banco de dados da instituição, mediante autorização formal prévia, perfazendo um total de 83 egressos, que foram contatados via e-mail e rede social. O convite enviado aos egressos continha informações sobre a pesquisadora e o estudo em curso. Após várias tentativas, obtiveram-se respostas de 44 participantes, destes, somente 11 atenderam aos critérios de inclusão. 
A coleta de dados deu-se entre os meses de junho e agosto de 2017, por intermédio de entrevista semiestruturada, mediada por roteiro previamente elaborado, contendo questões abertas, alinhadas aos objetivos traçados, que buscou caracterizar os participantes da pesquisa e sua percepção acerca da compreensão e desenvolvimento da competência clínica no âmbito da graduação. As entrevistas foram todas presenciais, em sala do grupo de pesquisa, envolvendo somente a pesquisadora principal e o egresso, que foi convidado em data e horário previamente agendado. Foram gravadas em áudio, mediante autorização, respeitando a disponibilidade e privacidade do participante. Tiveram duração média de 30 minutos. Para garantir o anonimato dos participantes na apresentação dos resultados, estes foram codificados usando a letra "E", inicial de "Egresso", seguida do número arábico referente à sequência de realização das entrevistas (E1 a E11).

A coleta de dados foi interrompida quando considerou-se que os elementos emergidos dos depoimentos propiciaram a compreensão do fenômeno em estudo, em sua singularidade e significado. Advoga-se que não se trata de saturação teórica, dada à complexidade do fenômeno, que dispõe de aspectos multidimensionais, permeados por interações e interconexões, logo, impossível esgotar-se numa única investigação (Minayo, 2017).

A análise dos dados seguiu as etapas da Análise Temática propostas por Braun \& Clarke (2006, 2019), a saber: 1) Familiarizando-se com os dados: após transcrição das entrevistas na íntegra, procedeu-se a imersão nos registros, explorando minuciosamente cada entrevista, e registrando-se a respectiva derivação dos significados apreendidos; 2) Gerando códigos iniciais: codificação sistemática dos elementos de cada entrevista, o que viabilizou o agrupamento inicial dos códigos; 3) Buscando por temas: reagrupamento de códigos por significado e semelhança, o que resultou na elaboração de temas potenciais, os quais reuniram um conjunto de significados compartilhados; 4) Revisando temas: análise criteriosa para verificar a funcionalidade do tema em relação aos códigos (partes) e ao conjunto dos dados brutos (todo), o que resultou na comparação dos dados e construção do mapa temático; 5) Definindo e nomeando temas: procedeu-se à etapa de reanálise para refinar as características inerentes à cada tema, e concomitantemente, consulta às notas registradas no processo de análise, o que culminou nas definições e nomes de cada tema; e, 6) Produzindo o relatório: considerada a última oportunidade de análise, foram identificadas as relações entre análise dos dados, perguntas de pesquisa, referencial teórico e literatura consultada, gerando um produto acadêmico qualificado.

Ressalta-se que a análise apresentada não ocorreu de forma linear, visto tratar-se de processo fluido e recursivo, no qual o pesquisador move-se de um lugar para o outro, ao longo das etapas. Desta análise emergiram os resultados, apresentados a partir de três temas: 1. "Elementos constitutivos da competência clínica e seu desenvolvimento no âmbito da graduação e pós-formado"; 2. "Dicotomias no processo ensino-aprendizagem que impactam no desenvolvimento da competência clínica"; e 3. "Interação professor - aluno - preceptor no desenvolvimento da competência clínica".

A investigação tem registro na Plataforma Brasil sob CAAE: 66122217.9.0000.5541, obedeceu às recomendações das resoluções do Conselho Nacional de Saúde 466/2012 e 510/2016, tendo sua aprovação do Comitê de Ética em Pesquisa do hospital universitário da instituição com o parecer número 2.178.422. Todos os participantes declararam concordância em participar, mediante assinatura em termo de consentimento livre e esclarecido.

\section{Resultados}

As participantes eram todas do sexo feminino, com faixa etária predominante entre 20 e 25 anos (54,55\%), com prevalência de atuação em unidade hospitalar (81,81\%). Da análise dos dados, apresentam-se três temas que elucidam as percepções dos egressos sobre o desenvolvimento da competência clínica na formação em enfermagem: 
Tema 1 - Elementos constitutivos da competência clínica e desenvolvimento no âmbito da graduação

Os egressos reconhecem elementos constitutivos da competência clínica durante o processo de formação na graduação, em especial, pela capacidade de identificação de manifestações clínicas do paciente. Compreendem que a competência clínica desenvolve-se de maneira processual, ao longo da vida, por meio da articulação indissociável entre teoria e prática, demanda raciocínio clínico e julgamento clínico, alcançados por meio da repetição / recorrência de situações. Assim, compreende-se que a competência clínica se desenvolve em campo prático, é nutrida pela experiência prévia (vivências pessoais), e dependente do tempo de permanência nos cenários reais de atuação.

Identificar as necessidades clínicas do paciente, saber quais manifestações ele está tendo, se é referente à clínica, se é pela doença, se é resposta à medicação ou algum outro problema. (E08)

\section{[...] o enfermeiro vai utilizar o conhecimento teórico vinculado ao conhecimento prático [...]. (E04)}

[...] a prática clínica está muito ligada à repetição, se você conseguir repetir aquilo várias vezes é uma competência que você desenvolve. (E10)

A expressa carência por mais tempo de prática clínica leva-os a defender a necessidade de internato no curso de enfermagem, e a optarem pelo abandono da assistência por não conseguir conduzir processos clínicos. Ainda, relacionam claramente o desenvolvimento da competência clínica à atuação em campos de práticas e estágio com maior fluxo de atendimentos e à figura do preceptor.

[...] muitas pessoas saem da prática também por isso, porque criam uma grande frustração de não saber intermediar, realizar determinados procedimentos, práticas, funções que são suas né. (E10)

Tema 2 - Dicotomias no processo ensino-aprendizagem e implicações no desenvolvimento da competência clínica

Nas falas dos egressos percebem-se dicotomias no processo de formação, relacionadas à implementação da estrutura curricular do curso, que pautado no modelo tradicional, em que cada semestre é tratado como independente, parecem desfavorecer a articulação teoria e prática, o diálogo entre professores, e entre professor e aluno, e expressa fragmentação acarretando lacunas e descontinuidades no processo ensino-aprendizagem.

Essa parte do procedimento foi falha porque, ou a gente não tinha oportunidade no campo onde a gente estava, ou porque a gente sempre usava esse tempo para discutir a parte teórica. (E08)

Cada bloco era específico numa área [...] a gente nunca conectava um semestre com o outro [...] o que poderia ajudar é se os blocos tivessem mais comunicação entre os professores, saber qual é a fragilidade de um aluno, para continuar desenvolvendo isso. (E08)

O sentimento que perpassa a vivência inicial do egresso na profissão é de ansiedade e inaptidão diante das múltiplas tarefas incumbidas a ele no cotidiano do trabalho. É manifestada ainda a complexidade inerente ao trabalho do enfermeiro e que exige do egresso competências técnica e gerencial. Entretanto, é mencionado o despreparo para exercê-las, bem como a necessidade de aprimoramento e atualização, o que é buscado por meio de residências e especializações. 
Como você se forma enfermeiro fazendo duas punções? Como você vai desenvolver outros procedimentos específicos se nem a punção você sabe fazer? (E10)

Quando você se forma você 'cai' no serviço, tem que fazer os dois, a clínica e o gerencial. E você não está preparado nem pra um e nem pra outro. (E10)

O enfermeiro é responsável pela sala, ele tem que saber se o monitor está funcionando [...] a gente nunca instalou uma medicação para correr numa bomba. Hoje eu vejo essa necessidade de estudar um pouco mais emergência, fazer uma especialização. (E02)

Tema 3 - Interação professor-aluno no desenvolvimento da competência clínica

Em relação às interações entre professor-aluno, os egressos consideram essencial ao desenvolvimento da competência clínica a atuação do docente como um facilitador, que lhe possibilite desenvolver autonomia, proatividade, autoconfiança, segurança, e que o estimule à construção permanente de conhecimentos.

Essa relação professor-aluno é essencial [...] se tem uma sondagem vesical, se é um professor que dá liberdade, que o aluno não tem medo, ele vai lá e vai tentar, porque ele sabe que se ele errar o professor vai corrigi-lo, mas não de forma punitiva. (E10)

Você não está numa guerra. Eu achava muita pressão, a gente até brincava: 'tropa de elite', é muita repressão, atrapalha a gente a aprender. [...] essa era a fragilidade, a questão do emocional e a ligação entre o professor e aluno. [...] Se você tiver confiança, se você estiver num lugar que você se sente bem, se sente apoiado, não tem como você não aprender. (E09)

Além da atuação dos professores, o conhecimento prático destes, adquiridos em suas vivências como enfermeiros, antes de se tornarem docentes, também foi mencionado como necessário ao desenvolvimento da competência clínica, pois, do contrário, transmitem insegurança por falta de conhecimento, e dificuldade em reunir melhores condições para proporcionar a articulação entre o conhecimento teórico e prático.

[...] Eu tive bastante professor que não teve vivência da prática. [...] Como que vai ensinar o fazer para o aluno sendo que ele não sabe? Não tem o conhecimento do fazer. (E01)

[...] quando você pega uma professora que tem uma vivência prática, ela consegue passar aquilo que é teórico, não dispensando a teoria, mas que é aplicável na realidade. (E06)

\section{Discussão}

O desenvolvimento da competência clínica é tema complexo, emaranhado por múltiplas dimensões, as quais envolvem a participação, responsabilidade e envolvimento de diferentes atores, processos e contextos, dentre estes, docentes, discentes, preceptores, gestores, proposta curricular do curso, cenários de prática em que os alunos são inseridos e, ainda, a historicidade da atenção à saúde, com seus avanços e retrocessos acerca das práticas de enfermagem (Pantoja \& Poblete, 2017). Nessa perspectiva, o primeiro tema de certa forma legitima tal complexidade, na medida em que percebe o desenvolvimento da competência clínica atrelado às experiências no ambiente clínico, e nutrido por vivências prévias e pelas oportunidades de prática propiciadas. 
Percebe-se, na compreensão dos egressos, que o desenvolvimento da competência clínica é potencializado com a atuação repetida em cenários de intervenção prática, fator estratégico para a oportunização de experiências múltiplas que concorrem para este desenvolvimento. Em suas vivências, o movimento de 'resgate' e mobilização de conhecimento demonstra se fazer constante, excedendo o plano da abstração, e materializando-se em ações concretas de cuidado.

Isso é importante de ser ponderado, pois a competência clínica é constituída por conhecimentos, habilidades, atitudes, capacidade de trabalhar em equipe, exercer a liderança, a gestão do cuidado, e análise de alterações apresentadas, o que corresponde à capacidade de julgamento clínico e, a partir dele, estabelecer ações de cuidado (Martínez-Momblán et al., 2020; Benner, 1984). Nesse sentido, está assentada na inextricável articulação entre teoria e prática, ou seja, na composição entre saber e saber-fazer, ambos inter-relacionados à atitude assumida pelo profissional, em ambiente clínico e em ações concretas (Martínez-Momblán et al., 2020), o que é relevante às práticas em prol do seu desenvolvimento, sobretudo no âmbito da graduação, pois as percepções apresentadas neste estudo mostram que, na experiência dos egressos, este desenvolvimento perpassa vários estágios de progressão, com continuidade na vida profissional.

Cabe considerar que Benner (1984) reforça a necessidade do processo de formação dar subsídios para que os alunos reconheçam, no decurso da graduação, a identidade do profissional enfermeiro, bem como as competências exequíveis para a execução das tarefas a ele incumbidas, nas esferas gerencial, assistencial, educacional e de pesquisa. Em sua obra intitulada From novice to expert, Benner (1984) resgata e evidencia o objeto de trabalho e as práticas de cuidado da enfermagem as quais envolvem aspectos relacionais, gerenciais, procedimentais, educacionais, dentre outros, deixando explícita a necessidade de que enfermeiros legitimem as ações praticadas, no intuito de dar visibilidade à responsabilidade que lhes compete.

Problematiza-se, portanto, que alguns egressos demonstram sentimentos de frustração diante de situações em que precisam pôr em prática a competência clínica em atividades privativas do enfermeiro, mas não se sentem seguros para tal. Nesta perspectiva, deve-se considerar a necessidade de promover experiências acadêmicas que propiciem o aprendizado clínico nos espaços de formação universitária, e que promovam a articulação de conhecimentos teóricos e práticos, oportunizando a aplicabilidade destes, a repetição e a reflexão, o que reforça o compromisso de formar profissionais competentes, críticos, reflexivos e resolutivos para atuar frente à realidade de saúde, de modo a atender as demandas do serviço, e realizar processos de análise constantes acerca da prática, e as quais promovam transformações e melhorias contínuas no processo de cuidar (Lüdke, Almeida \& Silva, 2017; Esteves et al., 2018; Almeida et al., 2020).

Salienta-se ainda que o conhecimento teórico torna-se significativo quando materializado em ações concretas, e quando é oportunizado ao aluno vivenciar a prática concomitantemente à teoria, favorecendo a conexão destes saberes. Para tanto, faz-se necessário inserir os alunos precocemente em cenários de prática, com vistas a aproximá-los da realidade dos serviços e à complexidade que detém estes espaços, mediados pela supervisão dos professores e também dos profissionais da área, denominados de preceptores (Lüdke, Almeida \& Silva, 2017; Almeida et al., 2020). Nesse escopo, os resultados do estudo e da literatura convergem no sentido de que é necessário rever e atualizar constantemente recursos e estratégias pedagógicas, no intuito de potencializar meios de integração entre teoria e prática, com maior interlocução entre os semestres, entre os componentes curriculares e entre os atores envolvidos no processo de formação.

A respeito destes atores, estudo recente desenvolvido na Áustria enfatiza a importância de que estudantes, professores e preceptores articulem entre si, uma proposta de ensino previamente planejada para acompanhamento dos estudantes. Para tanto, reforçam a necessidade de diálogo e da proposição de ações previamente pactuadas entre estes, de modo que os requisitos e objetivos do estágio fiquem claros para todos, favorecendo o processo de avaliação nestes espaços, e a realização de ajustes nas práticas do enfermeiro preceptor, para que sirvam de modelo para os estudantes, e propicie eficácia na supervisão clínica (Mueller, Mylonas \& Schumacher, 2018). 
Contudo, a função de supervisor, exercida por professores e preceptores na realidade deste estudo, parecem destoar desta perspectiva, se consideradas as experiências dos egressos que mostram que, mesmo em ambientes clínicos de aprendizagem, valorizam-se discussões dissociadas da prática, e oportunizam-se poucas práticas assistenciais. Esta realidade pode estar atrelada à falta de compartilhamento no planejamento, execução e avaliação do estágio, entre estes atores.

As percepções apresentadas pelos egressos sinalizam ainda para a importância de reconhecer que, para o desenvolvimento da competência clínica, é essencial: domínio e compartilhamento de saberes teórico e prático de enfermagem; experiência didática para propiciar a articulação destes conhecimentos; experiência assistencial como enfermeiro que possibilite ilustrar a aplicabilidade destes; e corresponsabilização entre discente, docente e preceptor, em todo o processo. Logo, é imperativo planejar as atividades práticas e estágios considerando as particularidades do contexto de inserção do trabalho, a etapa da formação do estudante e as necessidades de aprendizagem de cada estudante, visualizando, refletindo e buscando estratégias colaborativas para preencher continuamente as lacunas presentes no processo de formação.

Essa compreensão fica evidente nas falas dos egressos que desaprovam a avaliação somente ao final de cada prática ou do estágio supervisionado, na medida que impossibilita reconhecer suas fragilidades durante o processo e desenvolver-se ainda na etapa de formação em curso. Do mesmo modo, encontra-se sustentação em recomendações da literatura que orienta que tais lacunas devam ser identificadas através de processos avaliativos construtivos, formativos e somativos, considerando as necessidades de aprendizado e as competências desenvolvidas pelos estudantes, em processo contínuo, com feedback entre os sujeitos, para que ambos tenham oportunidade de explicitar pontos necessários de aperfeiçoamento (Esteves et al., 2019).

Além disso, quando há boa interação entre enfermeiros docente e preceptor no processo de supervisão clínica, evidenciam-se resultados positivos na aprendizagem e no desempenho do estudante, maior integração ensino-serviço, e impactos positivos na dinâmica do trabalho em saúde (Mueller, Mylonas \& Schumacher, 2018).

Em meio à discussão apresentada, cabe frisar o papel dos preceptores no decurso dos estágios supervisionados. A supervisão destes profissionais é recomendada pelas Diretrizes Curriculares Nacionais para os Cursos de Graduação em Enfermagem (Brasil, 2001), e tem por objetivo superar a aprendizagem mecânica, resultante da mera realização de tarefas, por uma aprendizagem significativa, contextualizada, geradora de reflexão sobre a ação, com foco principal no desenvolvimento de competências clínicas. Sob tais diretrizes, a atuação propositiva destes profissionais mostra-se primordial, visto que estes conhecem as peculiaridades presentes no contexto do trabalho, e quando cientes das competências que precisam ser desenvolvidas pelos estudantes, identificam necessidades de aprendizagem destes, sendo atores potencialmente estratégicos para integrá-los no serviço (Esteves et al., 2019).

Nesse escopo, faz-se relevante adotar estratégias de condução das práticas, tais como adequá-las ao horário de funcionamento das unidades e à sua dinâmica como um todo, de modo a integrar os alunos à realidade do serviço, aos processos de trabalho, bem como aos usuários e comunidade em suas particularidades, oportunizando práticas que possam ir além da mera execução de técnicas e do cumprimento da agenda de atendimentos.

No cenário hospitalar, a compreensão de fluxos e processos mostra-se igualmente fundamental, podendo constituir oportunidade ímpar ao desenvolvimento da competência clínica, a passagem de plantão, pois é neste momento em que muitas trocas sobre a condição clínica dos pacientes pode ser disparadoras de posterior investigação, discussão e implementação de ações práticas de cuidado com base nas necessidades de saúde destes. Sob tal aspecto, a literatura aponta que a imersão dos estudantes em espaços que oportunizam o desenvolvimento da prática clínica, possibilitam a articulação teoria-prática, bem como a aquisição e acúmulo de experiências, tornando os futuros enfermeiros aptos e seguros para o exercício profissional (Esteves et al., 2019).

Neste contexto, a vivência em cenários de prática, supervisionados por docentes e enfermeiros experientes, permite ao aluno aplicar o conhecimento teórico às ações em curso, reforçando a assertiva de que, não existe teoria sem prática ou prática 
sem teoria, ambas coexistem. A teoria sem a prática não se concretiza em ações ou transformações sobre o mundo. De outro lado, a prática sem a teoria pode tornar-se repetitiva, reprodutiva, porque irrefletida (Progianti et al., 2019; Esteves et al., 2018).

Para a superação da dicotomia teoria e prática, os egressos mencionaram como imprescindível a interdisciplinaridade, visto que as disciplinas no processo de formação acontecem de forma independente, desarticulada. Estudos descrevem o estágio supervisionado como o espaço / momento propício para consolidar aprendizagens, de modo a integrar os diversos saberes oriundos das aulas teóricas e, necessários à prática (Progianti et al., 2019; Esteves et al., 2019). Destarte, a prática é considerada atividade ímpar, em que educação, pesquisa e gestão do trabalho se constituem em funções indissociáveis, e a base de sustentação dessa prática é a mobilização de conhecimentos teóricos acumulados ao longo do curso.

Um dos aspectos considerado relevante para mediar à superação da dicotomia teoria e prática é promover a integração entre instituição de ensino, serviços de saúde, alunos e pacientes. Abreu (2007, p. 95) cita estudo de Hart e Roten (1995), que identificaram seis fatores em contexto clínico que dão subsídios para uma formação de qualidade, a saber “autonomia e reconhecimento, clareza do papel a desempenhar, satisfação profissional, suporte dos pares, oportunidades de aprendizagem e qualidade da supervisão".

Em geral, essa (des)integração é tratada por atores isolados, imbuídos do desejo ou mesmo necessidade de promover articulações pessoais, no intuito de garantir a ocupação de cenários de prática, hoje tão disputados pelas inúmeras escolas de enfermagem. Todo esse processo resulta na revelação aos alunos, acerca da (co)existência de uma enfermagem ideal e outra real, antagônicas, podendo gerar sentimentos de frustração nos estudantes, desestimulando-os a trilhar o caminho da prática clínica.

A assertiva acima, corrobora com estudo de Progianti et al., (2019) que buscou compreender a vivência de sofrimento e prazer dos acadêmicos de enfermagem, revelando que vivenciar situações conflituosas de cuidado, bem como relações interpessoais de desrespeito geram nos alunos sentimentos de angústia, impotência e desencorajamento, podendo repercutir de forma negativa sobre a caracterização do perfil profissional dos futuros enfermeiros, e na construção identitária com a profissão, levando-os à desmotivação.

Acredita-se que a integração academia-serviço seja uma alternativa valiosa, com perspectiva de garantir os benefícios necessários aos dois segmentos - de um lado, a academia se nutre do conhecimento prático, necessário à atualização docente e desenvolvimento de competências dos alunos, e de outro, o serviço, se beneficia pelo compartilhamento de melhores evidências científicas, com consequentes melhorias para a qualidade do cuidado de enfermagem (Almeida et al., 2020).

Para a concretização dessa importante estratégia de retroalimentação é imperativo que as instituições - academia e serviço, estabeleçam projetos de integração, por meio dos quais professores e preceptores passem a interagir de forma sistematizada e contínua. $\mathrm{O}$ encontro entre esses atores, na perspectiva apontada, pode se constituir em estratégia que garanta a qualificação de ambos os processos - a formação de enfermeiros que tenham identidade com a profissão e a qualificação do cuidado de enfermagem aos usuários do Sistema Único de Saúde (Nocerino \& Chiarini, 2018; Almeida et al., 2020).

Neste sentido, compreende-se que o ser professor e ser enfermeiro são competências necessárias e indissociáveis, dimensões da docência que se complementam e se articulam, e são (re)construídas a partir das interações que se estabelecem, ou seja, a identidade de professor se constrói à medida que acontece o exercício de ser enfermeiro, mediante o processo de trabalho e a constituição do saber prático (Nocerino \& Chiarini, 2018).

Assim, é fundamental que professores mantenham constante contato com a prática assistencial, para que suas competências como enfermeiro não se estagnem, e o aluno reconheça no professor, uma referência profissional. O ‘modelo’ de evitação da prática de cuidar, pelos professores, pode levar o aluno a ter dificuldade de identificar o papel do enfermeiro no serviço, bem como suas competências e responsabilidades. O professor, munido de experiência, demonstra segurança no 
desenvolvimento das práticas, e o aluno, por sua vez, através da interação com esse professor sente-se mais seguro e estimulado a realizar atividades sob supervisão (Almeida et al., 2020). Porém, ainda que se considere necessária a autorreflexão, reconhecimento de limitações, responsabilidade pela construção do saber - conhecimento prático, esta não é exclusiva do professor, mas também responsabilidade institucional, a quem cabe criar condições para que docentes se capacitem / atualizem permanentemente (Nocerino \& Chiarini, 2018).

Por último, cabe destacar que a integração academia-serviço, para além do já exposto, certamente contribui com a valorização e reconhecimento, pela sociedade, da profissão de enfermeiro (Almeida et al., 2020).

\section{Considerações Finais}

O estudo possibilitou compreender a premente necessidade das instituições de ensino em pensar a formação dos alunos de forma integrada aos serviços, ao destacar a importância da aproximação do aluno ao campo prático. O contato com situações reais do cotidiano e o exercício de atividades privativas do enfermeiro leva-os a contemplar as funções inerentes à profissão. Também possibilita a aquisição de experiências que contribuem para a religação de saberes múltiplos, o que minimiza as dicotomias existentes entre a teoria-prática.

A partir dos resultados, considera-se que essa articulação é dependente de fatores variados, dentre eles mudanças na política educacional, no cenário das práticas e na integração entre docentes e preceptores. Portanto, trata-se de processo complexo que exige participação ativa e democrática de todos os atores envolvidos.

O desenvolvimento da competência clínica depende de interações e do estilo de interações adotados na supervisão das atividades do curso. Há basicamente dois estilos ou extremos no processo interacional - o professor que se reconhece como mediador entre o aluno e o conhecimento, e busca incentivar a construção permanente de saberes e, o professor que assume posição mais autocrática, e busca nas interações, a devolutiva das aprendizagens obtidas no processo.

No processo de formação, os alunos veem no professor e preceptor uma referência a ser mimetizada, e para tanto, necessitam que a relação seja permeada por atitudes de respeito, encorajamento, empatia. Por fim, cabe ressaltar que a complexidade do fenômeno em estudo, abarcado por múltiplas dimensões, possibilitou apreender algumas facetas do objeto de estudo, do qual pode-se afirmar que são oportunos o desenvolvimento de novas pesquisas sobre esta temática, principalmente em relação ao desvelamento do conceito de competência clínica, evidenciando sua multidimensionalidade, bem como pesquisas metodológicas que elaborem construtos capazes de aferir tal competência em graduandos de enfermagem.

\section{Referências}

Abreu, W. C. (2007). Formação e aprendizagem em contexto clínico. Fundamentos, teorias e considerações didácticas. Coimbra, Formação e Saúde.

Almeida, V. L. M., Alves, V. H., Rodrigues, D. P., Marchiori, G. R. S., Dulfe, P. A. M., \& Vieira, B. D. G., et al. (2020). Theoretical-practical teaching in Nursing in women's health: an experience report. Research, Society and Development, 9(9), 1-14.

Benner, P. (1984). From novice to expert: Excellence and Power in Clinical Nursing Practice. New York, Addison Wesley Publishing.

BRASIL. (2001). Resolução CNE/CES No 3, de 7 de novembro de 2001. Brasília: Conselho Nacional de Educação.

Braun, V., \& Clarke, V. (2008). Using thematic analysis in psychology. Qualitative Research in Psychology, 3(2), 77-101.

Braun, V., \& Clarke, V. (2019). Reflecting on reflexive thematic analysis. Qualitative Research in Sport, Exercise and Health, 11(4), $589-597$.

Esteves, L. S. F., Cunha, I. C. K. O., Bohomol, E., \& Negri, E. C. (2018). Supervised internship in undergraduate education in nursing: integrative review. Revista Brasileira de Enfermagem, 71(supl 4), 1740-1750.

Esteves, L. S. F., Cunha, I. C. K. O., Bohomol, E., \& Santos, M. R. (2019). Clinical supervision and preceptorship/tutorship: contributions to the Supervised Curricular Internship in Nursing Education. Revista Brasileira de Enfermagem, 72(6), 1730-1735.

Leal, L. A., Soares, M. I., Silva, B. R, Bernardes, A., \& Camelo, S. H. H. (2018). Clinical and management skills for hospital nurses: perspective of nursing university students. Revista Brasileira de Enfermagem, 71(Supl 4), 1514-1521. 
Research, Society and Development, v. 10, n. 9, e14610917561, 2021

(CC BY 4.0) | ISSN 2525-3409 | DOI: http://dx.doi.org/10.33448/rsd-v10i9.17561

Lüdke, M., Almeida, E. B., \& Silva, A. L. B. (2017). Contribuciones de la Etapa Supervisada para la Formación de la Identidad Profesional de las enfermeras. Cultura de los Cuidados, 21(48), 131-139.

Martínez-Momblán, M. A., Colina-Torralva, J., De la Cueva-Ariza, L., Guix-Comellas, E. M., Romero-García, M., \& Delgado-Hito, P. (2020). Analysis of the evolution of competences in the clinical practice of the nursing degree. Revista Latino-Americana de Enfermagem, 28:e3231, 1-8.

Minayo, M. C. S. (2017). Amostragem e saturação em pesquisa qualitativa: consensos e controvérsias. Revista Pesquisa Qualitativa, 5(7), 1-12.

Mueller, G., Mylonas, D., \& Schumacher, P. (2018). Quality assurance of the clinical learning environment in Austria: Construct validity of the Clinical Learning Environment, Supervision and Nurse Teacher Scale (CLES+T scale). Nurse Education Today, 66, 158-65.

Nocerino, R., \& Chiarini, M. (2018). The concept of professional identity in nursing students and practitioners: a research protocol of a cross-sectional study. Senses and Sciences, 5(4), 641-648.

Pantoja, C. C., \& Poblete, C. C. (2017). "Prácticas Clínicas”: Reflexiones personales a lo largo del caminho. RIECS, 2(1), 28-3.

Progianti, J. M., Souza, M. N., Oliveira, E. B., Rodrigues, F. A. B., Prata, J. A., \& Vargens, O. M. C. (2019). Suffering and pleasure experiences of nursing undergraduate students in maternity. Revista de enfermagem da UERJ, 27:e39620, 1-7.

Rocha, E. N., Mantovani, M. F., Silva, A. T. M., Hereibi, M. J., Viante, W. J. M., \& Kwiatkoski, D. R. (2019). Nursing students' perception of clinical competences. REME - Rev Min Enferm, 23:e-1179, 1-6.

Sadeghi, A., Oshvandi, K., \& Moradi, Y. (2019). Explaining the inhibitory characteristics of clinical instructors in the process of developing clinical competence of nursing students: a qualitative study. Journal of Family Medicine Primary Care, 8(5), 1664-1670.

Souza, V. R., Marziale, M. H., Silva, G. T., \& Nascimento, P. L. (2021). Tradução e validação para a língua portuguesa e avaliação do guia COREQ. Acta Paulista de Enfermagem, 34:eAPE02631, 1-9.

Unsworth, J., Melling, A., \& Porteous, D. (2020). Developing an integrated approach to the assessment of student nurse competence using the Total Client Care (TCC) assessment tool. Nurse Education in Practice, 44, 1-6.

Vreugdenhil, J., \& Spek, B. (2018). Development and validation of Dutch version of Lasater Clinical Judgment Rubric in hospital practice: An instrument design study. Nurse Education Today, 62, 43-51. 